\title{
Painful Distal Phalanx Toe Pseudoarthrosis Surgically Treated: A Case Report
}

\author{
Henrique Mansur ${ }^{1 *}$, Lucas Sacramento Ramos ${ }^{2}$, Bruno Povoleri Marano ${ }^{2}$ \\ ${ }^{I}$ PhD, Department of Orthopaedics Surgery, University of Brasília, Brasilia, Distrito Federal, Brazil \\ ${ }^{2}$ MD, Department of Orthopaedics Surgery, Regional Hospital of Planaltina, Planaltina, Distrito Federal, \\ Brazil
}

*Corresponding Author: Dr. Henrique Mansur, Bloco G - Lote 09, Shln - Asa Norte, Brasília - DF, 70770-560,Brazil, Email: henrimansur@globo.com

\begin{abstract}
Fracture of the phalanges is the most common of the forefoot. Complications following fractures of the lesser toes are rare. A potential complication is the non-union, which is usually asymptomatic and does not cause function limitation. Here, we report, for the first time, the case of a 45-year-old female runner who had a fourth toe distal phalanx fracture. Following 2 months of conservative treatment, she persisted with pain and inability to run. Surgical treatment with calcaneus bone graft and phalanx fixation provided an excellent result. Non-union is a potential complication following phalanges fractures, and surgical treatment through a curved lateral approach is an option of treatment when there is a functional limitation.
\end{abstract}

Level of Evidence: Case report (Level V)

Keywords: digital and sesamoid fractures; forefoot; foot surgery techniques; diagnostic and therapeutic techniques; pseudoarthrosis.

\section{INTRODUCTION}

The phalanges are small bones of the toe that assist in balance and push-off stage of gait ${ }^{1}$. Fracture of the phalanges is the most common of the forefoot, representing $3.6 \%$ to $8 \%$ of all lower extremity injuries ${ }^{2,3}$. The most common mechanisms are a direct trauma with a heavy object dropping onto the toe or the "nightwalker fracture" with the abduction of the lesser toes striking a table leg ${ }^{2,4}$. These fractures can have a simple pattern or severe comminution with associated dislocation ${ }^{4}$.

Lesser toes phalanges fractures are mostly treated conservatively with adhesive taping ${ }^{1}$. Surgical treatment is reserved for fractures with significant angulation that cannot be reduced closed. Post-traumatic arthritis, mal-union, or pseudoarthrosis can cause persistent pain which can be treated with arthrodesis or exostectomy ${ }^{1,4}$.

There is only one study that describes a case of symptomatic pseudoarthrosis of a lesser toe distal phalanx, surgically treated with arthrodesis $^{5}$. To the best of our knowledge, this is the first case reported of a painful non-union of a distal phalanx fracture of the fourth toe treated surgically by osteosynthesis, in a runner. Open fixation of the phalanx with autologous calcaneus bone graft through a curved incision along the lateral border of the toe let to fracture consolidation and pain relief.

\section{CASE RePort}

A 45-year-old female amateur runner presented to our outpatient clinic 2 months after she had a direct trauma in her fourth left toe. She stated that she had attended the emergency department immediately after the injury and that foot radiographs were taken (Fig. 1), with a diagnosis of a distal phalanx fracture. The patient was discharged with adhesive taping including the $3^{\text {rd }}, 4^{\text {th }}$, and $5^{\text {th }}$ toes placed in a below-knee non-weight bearing plaster cast for 10 days, followed by 4 weeks of weight-bearing with a walking boot. Two months after the initial trauma, because the swelling did not subside and the pain continued, she presented to our outpatient clinic for further medical help. On physical examination, swelling and 
tenderness over the toe tip and nail ecchymosis were present. Radiographs and computed tomography (CT) was performed and identified a pseudoarthrosis of the distal phalanx (Fig. 2). The patient couldn't make physical activities like jogging or run, thus, surgical treatment was decided.

The patient received ankle block anesthesia. A curved incision along the lateral border of the toe was performed (Fig. 3). After the excision of the fibrous tissue, the distal phalanx fracture was filled with calcaneus bone graft and fixated with a $1.2 \mathrm{~mm}$ cortical screw. The patient was discharged after 24 hours. Rehabilitation involved post-surgery shoe without weightbearing for up to two weeks following by four weeks with full load discharge. At 3 months postoperatively, the patient had no symptoms and had returned running. Radiographs at six months postoperatively showed graft integration and phalanx fracture consolidation (Fig. 4).

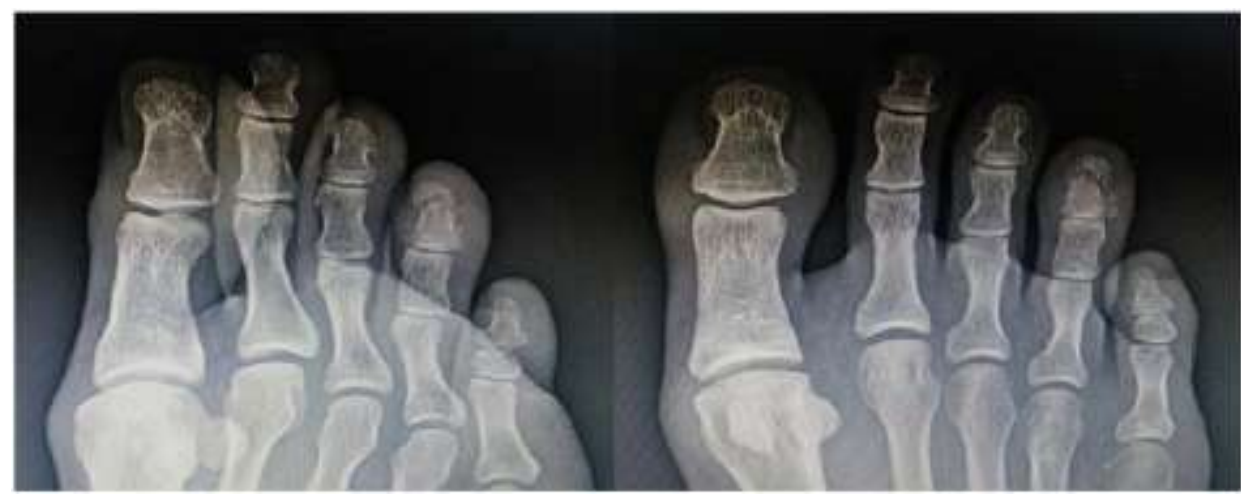

Fig.1. Radiograph anteroposterior view taken in the day of the trauma. Note the comminuted fracture of the distal phalanx of the fourth toe

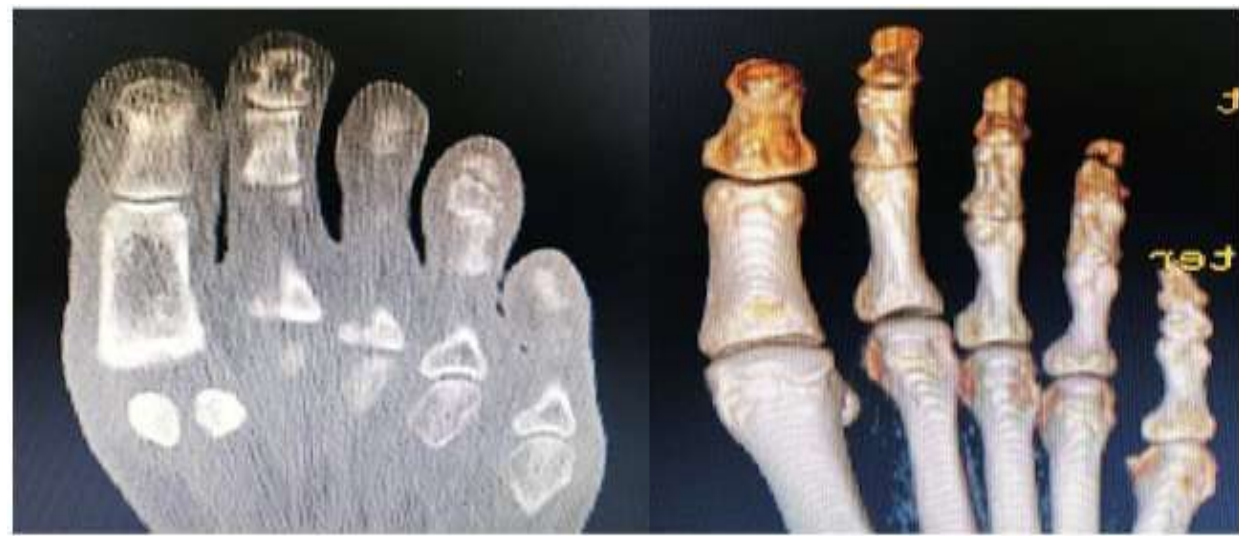

Fig.2. CT scan performed two months after the trauma. Note the pseudoarthrosis of the distal phalanx of the fourth toe

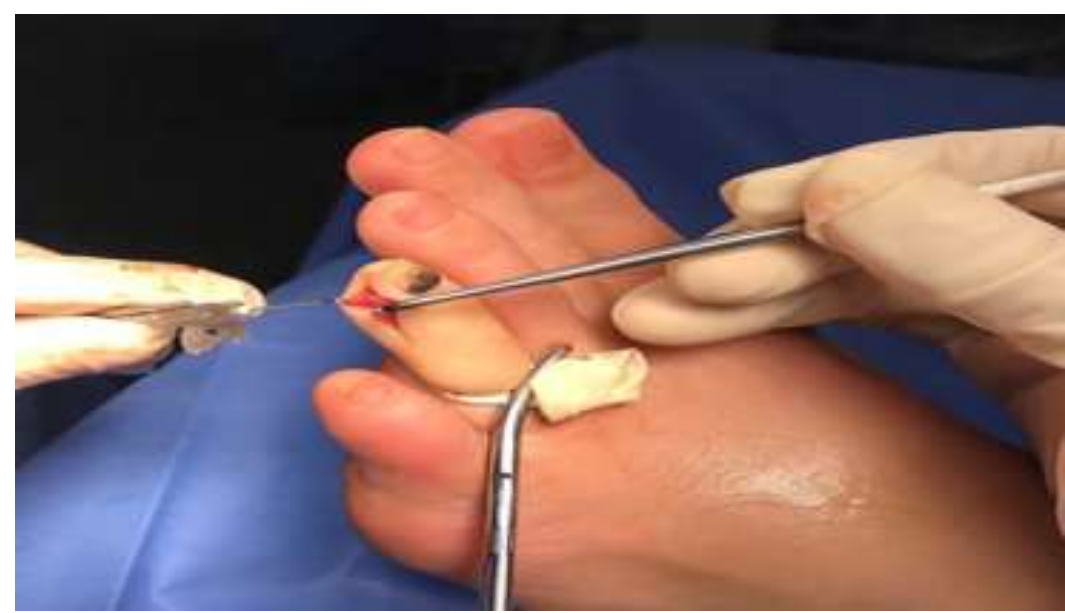

Fig.3. Curved incision along the lateral border of the 4th toe ischemic with a gloved finger 


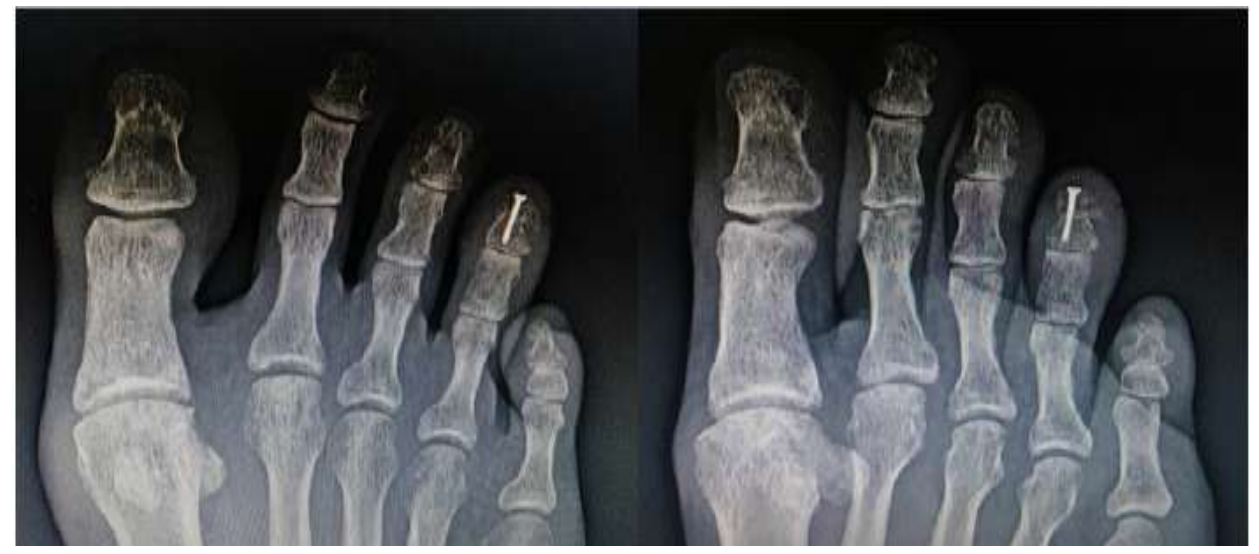

Fig.4. Postoperative radiographs anteroposterior, oblique and lateral views. Note the distal phalanx consolidation 6 months after fixation with a $1.2 \mathrm{~mm}$ cortical screw and calcaneus bone graft

\section{DISCUSSION}

Complications following fractures of the lesser toes are rare, even in the setting of residual malalignment and loss in the range of motion of the involved toe6. Pseudoarthrosis of phalanges fracture is a rare complication, with a scarce description in the literature ${ }^{1,4}$. In general, the treatment of pseudoarthrosis requires bone fixation and, usually, the addition of bone graft ${ }^{7}$.

Foo and Wee described the only case of pseudoarthrosis of the distal phalanx in a 60year-old female with symphalangism involving the middle and distal phalanges of the $4^{\text {th }}$. Five months after the initial injury the patient underwent surgical treatment with proximal inter-phalangeal arthrodesis through a transverse dorsal incision ${ }^{5}$. Similarly, our patient had pseudoarthrosis of the distal phalanx of the 4th toe, however, we chose for the osteosynthesis through a curved incision along the lateral border of the toe. Besides synthesis preserves the joint mobility, it reduces arthrodesis complications like malalignment and non-union. Only $72 \%$ of bone fusions after proximal interphalangeal arthrodesis for the treatment of mallet toes werereported ${ }^{8}$. Moreover, the lateral incision avoids damages to the extensor tendons, once it has been related to worse clinical outcomes, higher complication rates, and longer recovery time in phalanges osteotomies for correction of lesser toes deformities ${ }^{9}$.

Imade et $\mathrm{al}^{10}$ reported a case of a fracture of the proximal phalanx of the hallux fixed with kwires, in a 25-year-old male patient. After eight months, he evolved with pseudoarthrosis and underwent a new surgery with intramedullary fixation with a bone peg and iliac bone graft. In our case, we decided to do the intervention as soon as the pseudoarthrosis was diagnosed, two months after the initial trauma, shortening her return to sports activities. In athletes, the goal of treatment is to achieve a more predictable fracture healing process, reducing the time to return to physical activities ${ }^{11}$. Lastly, differently from the authors, we used a calcaneus graft to reduce the morbidity of the procedure, since no difference was found between iliac crest and calcaneus for bone graft regarding consolidation rates for foot and ankle surgeries ${ }^{12}$.

As the main limitation of our study, we can mention the short follow-up period. However, our patient had a good outcome, returning to work and recreational sports activities and it is an injury with low morbidity and risk of late complications. We believe that further studies about this topic, especially in athletes, are necessary to find better treatment options.

\section{CONClusion}

We described a unique case of a runner who sustained a distal phalanx fracture of the fourth toe, evolving to pseudoarthrosis, despite the conservative treatment. The patient underwent surgical treatment with fracture fixation and calcaneus bone graft with an excellent result. We believe that early treatment allowed the patient to return her daily living and recreational activities without limitations.

\section{CONFLICTS OF INTEREST}

None

\section{REFERENCES}

[1] Coughlin M, Saltzman C, Anderson RB. Mann's surgery of the foot and ankle, 9th ed. Philadelphia, Elsevier, 2014, Vol 2 pp 2177 2184.

[2] Myerson MS: Injuries to the forefoot and toes. Disorders of the foot and ankle: medical and surgical management, ed 2, Philadelphia, 1991, WB Saunders, Vol 3, pp 2242-2249. 
[3] Court-Brown CM, Caesar B. Epidemiology of adult fractures: a review. Injury. 2006;37:691697. doi:10.1016/j. injury.2006.04.130

[4] Rockwood JR CA, Green DP, Bucholz RW. Fraturas em adultos, ed 8. Barueri, SP, 2016, Manole, Vol 1 pp 2689-2694.

[5] Foo GL, Wee LHJ. Surgical Fixation and Interphalangeal Arthrodesis of Symptomatic Nonunion of Fracture of a Lesser Toe Distal Phalanx: A Case Report. Malays Orthop J. 2019 Nov; 13(3): 69-71.

[6] Lee DK, Mulder GD, Schwartz AK. Hallux, sesamoid, and first metatarsal injuries. ClinPodiatr Med Surg. 2011;28:43-56.

[7] Schenk RK, Müller ME, Willenegger $\mathrm{H}$. Experimental Histological Contribution to the Development and Treatment of Pseudarthrosis. HefteUnfallheilkd. 1968;94:15-24.

[8] Malhotra K, Davda K, Singh D. The pathology and management of lesser toe deformities. EFORT open reviews. 2016;1(11):409-19.
[9] Nieto-García E, Ferrer-Torregrosa J, RamírezAndrés L, Nieto-González E, Martinez-Nova A, Barrios C. The impact of associated tenotomies on the outcome of incomplete phalangeal osteotomies for lesser toe deformities. JOrthopSurgRes. 2019;14(1):308.

[10] Imade S, Miyamoto W, Sanada H, Mori R, Uchio $Y$. Nonunion in proximal phalanx of great toe treated by grafting with precisely processed autologous bone peg. J Foot Ankle Surg. 2011;50(4):449-52.

[11] Baumfeld T, FernandesRezende R, Nery C, Batista JP, Baumfeld D. Fifth Metatarsal Fractures in Professional Soccer Players: Case Series. Foot Ankle Spec. 2020;1938640020911223.

[12] Raikin SM, Brisin K. Local bone graft harvested from the distal tibia or calcaneus for surgery of the foot and ankle. Foot Ankle Int. 2005;26(6):449-53

Citation: Henrique Mansur, Lucas Sacramento Ramos, Bruno Povoleri Marano. "Painful Distal Phalanx Toe Pseudoarthrosis Surgically Treated: A Case Report”. 2021; 6(1):7-10. DOI: https://doi.org/10.20431/24560588.0601002 .

Copyright: (c) 2021 Authors. This is an open-access article distributed under the terms of the Creative Commons Attribution License, which permits unrestricted use, distribution, and reproduction in any medium, provided the original author and source are credited. 